UDK 528.14

\title{
GPS VIRTUALIOSIOS REFERENCINĖS STOTIES REGRESINIS MODELIS
}

\author{
Jonas Skeivalas \\ Geodezijos ir kadastro katedra, Vilniaus Gedimino technikos universitetas, \\ Sauletekio al. 11, LT-10223 Vilnius, Lietuva, \\ el.paštas: Jonas.Skeivalas@ap.vtu.lt
}

Iteikta 200605 03, priimta 20060921

\begin{abstract}
Santrauka. Straipsnyje pateikiamas GPS metodu nustatytų koordinačių, nešlio fazių skirtumų bei pseudoatstumų pataisų skaičiavimo, taikant regresinį modeli, principas. Regresinių lygčių parametrų reikšmės apskaičiuojamos pagal tikslias žinomas referencinių stočių koordinates bei išmatuotų atitinkamų dydžių reikšmes, taikant mažiausiujjų kvadratų metodą. Prognozinio pataisų nustatymo modelio tikslumas įvertinamas kovariacijų matricomis.
\end{abstract}

Prasminiai žodžiai: GPS referencinès stotys, regresinis pataisų prognozavimo modelis.

\section{Ivadas}

Pastaraji dešimtmetị plačiai pradètas taikyti diferencinis koordinačių nustatymo metodas (DGPS).

GPS referencinès stotys transliuoja GPS signalu vartotojams koordinačių pataisas arba nešlio fazių skirtumų ir pseudoatstumų pataisas. Šios pataisos gali būti taikomos realiojo laiko masteliu arba skaičiuotojams tinkamu laiku (post-processing režimu). Tam tikro skaičiaus GPS referencinių stočių matavimų duomenys apibendrinami ir sisteminami virtualiosiose referencinèse stotyse, taikant atitinkamą modeli [1-9]. Taip patikimiau ir tiksliau nustatoma GPS signalu vartotojų padėtis, priimant jau apdorotus ir iš virtualiuju stočių tam tikro modelio pavidalu transliuojamus signalus.

Straipsnyje siūlomas regresinis virtualiujų GPS stočių vartotojo imtuvo pataisų prognozavimo modelis. Prognozavimo modelio parametrų reikšmès nustatomos mažiausiuju kvadratų metodu. Tam taikomos GPS referencinių stočių koordinačių pataisos ir nešlio fazių skirtumų bei pseudoatstumų pataisos. Analizuojamas pataisų modelių tikslumas.

\section{Teorinès prielaidos. Koordinačių, nešlio fazių bei pseudoatstumų pataisų variantas}

GPS referencinių stočių transliuojamas koordinačių, pseudoatstumų ir nešlio fazių pataisas fiksuotu laiko momentu nedideliu atstumu (maždaug iki $10 \mathrm{~km}$ ) tarp GPS referencinès stoties ir naudotojo imtuvo galima laikyti pastoviomis. Tai apibrěžia troposferos ir jonosferos būklè $[1,10]$. Todèl, referencines stotis išdèsčius didesniu atstumu, tenka sukurti GPS virtualiąsias stotis, kurios transliuoja iš referencinių stočių duomenų sudarytus pataisų modelius. Šie modeliai transliuojami nedelsiant (realiuoju laiku), bet gali būti naudojami ir post-processing režimu, t. y. vartotojui patogiu laiku. Vartotojo padeties koordinačiu pataisos arba pseudoatstumų bei nešlio fazių pataisos priklauso nuo atstumo tarp vartotojo ir virtualiosios stoties bei krypties i šią stotị [1, 2].

Kadangi GPS referencinès stotys irengiamos taškuose, kurių koordinatès tiksliai žinomos (su keleto milimetru ar centimetrų klaidomis), tai kiekviena GPS referencinè stotis pagal priimtus DŽP (dirbtinių Žemès palydovu) kodinius ir nešlio signalus nustatydama savo koordinates gali apskaičiuoti išmatuotų koordinačių, pseudoatstumų bei nešlio fazių skirtumų pataisas. Taigi galime parašyti:

$$
\begin{aligned}
& \delta \boldsymbol{T}_{\boldsymbol{i}}=\tilde{\boldsymbol{T}}_{\boldsymbol{i}}-\boldsymbol{T}_{\boldsymbol{i}}, \\
& \delta \boldsymbol{\Phi}_{i}^{k}(t)=\tilde{\boldsymbol{\Phi}}_{i}^{k}(t)-\boldsymbol{\Phi}_{i}^{k}(t), \\
& \delta R_{i}^{k}(t)=\tilde{R}_{i}^{k}(t)-R_{i}^{k}(t),
\end{aligned}
$$

čia $\delta \boldsymbol{T}_{i} \rightarrow\left(\delta X_{i}, \delta Y_{i}, \delta Z_{i}\right)^{T}-i$-tosios referencinès stoties koordinačių pataisu vektorius; $T_{i} \rightarrow\left(X_{i}, Y_{i}, Z_{i}\right)^{T}-$ išmatuotų apytikrių koordinačių vektorius; $\tilde{T}_{i} \rightarrow\left(\tilde{X}_{i}, \tilde{Y}_{i}, \tilde{Z}_{i}\right)^{T}-$ tikslių koordinačių vektorius; $\delta \Phi_{i}^{k}(t)-i$-tosios referencinès stoties nešlio fazių pataisa ciklais laiko momentu $t$, kai priiminejami $k$-tojo palydovo signalai; $\delta R_{i}^{k}(t)-i$-tosios referencinès stoties pseudoatstumų pataisa laiko momentu $t$, kai priiminėjami $k$-tojo palydovo signalai; $\Phi_{i}^{k}(t), \tilde{\Phi}_{i}^{k}(t), \quad R_{i}^{k}(t), \tilde{R}_{i}^{k}(t)-$ atitinkamų dydžių išmatavus gautos ir tiksliosios reikšmès.

GPS vartotojas tikslias savo $A$ taško koordinates apskaičiuoja pagal išmatuotus atitinkamus dydžius, t. y. koordinates, nešlio fazių skirtumus arba pseudoatstumus bei pridedamas GPS referencinių stočių transliuojamas šių dydžių pataisas. Skaičiavimams galima panaudoti bet kuriuos pavienès referencinès stoties duomenis. Tačiau 
taško $A$ koordinatės tiksliau nustatomos naudojant visu GPS referencinių stočių matavimo duomenis. Šiam tikslui sukuriama GPS virtualioji referencinè stotis.

Nešlio fazių skirtumų pataisos $\delta \Phi_{i}^{k}(t)$ bei pseudoatstumų pataisos $\delta R_{i}^{k}(t)$ nustatomos referencinèse stotyse kaip GPS imtuvais išmatuotų nešlio fazių skirtumų bei pseudoatstumų nuokrypiai nuo tikrujų jų reikšmių. Tikrosiomis nešlio fazių skirtumų bei pseudoatstumų reikšmėmis laikomos reikšmės, apskaičiuotos pagal žinomas tikslias referencinių stočių koordinates.

\section{GPS virtualiosios referencinès stoties modelio parametrų reikšmių nustatymas}

Regresinio modelio parametrų reikšmėms skaičiuoti taikysime tiesini modelị, užrašomą parametrinių lygčių sistema:

$$
\delta \tilde{\boldsymbol{F}}=\boldsymbol{A} \tau,
$$

čia $\delta \tilde{\boldsymbol{F}} \rightarrow \delta \tilde{\boldsymbol{T}}, \quad \delta \tilde{\boldsymbol{\Phi}}(t), \quad \delta \tilde{\boldsymbol{R}}(t)$ - referencinių stočių išlygintujų koordinačių pataisų arba nešlio fazių skirtumu pataisu ar pseudoatstumu pataisų vektoriai; $\boldsymbol{A}$ parametrinių lygčių koeficientų matrica; $\boldsymbol{\tau}=\left(t_{1}, t_{2} \ldots t_{k}\right)^{T}-$ determinuotuju parametrų išlygintuju reikšmių vektorius.

Parametrinių lygčiu sistemos, siekiant ivertinti koordinačių, nešlio fazių skirtumų ir pseudoatstumu pataisas, rašomos atskirai. Tam naudojami visų tam tikros teritorijos referencinių stočių atitinkamų epochų matavimų duomenys.

Parametrinių lygčių sistema (4) paverčiama pataisu lygčių sistema:

$$
\boldsymbol{V}=\boldsymbol{A} \tau-\delta \boldsymbol{F},
$$

čia $\boldsymbol{V}=\delta \tilde{\boldsymbol{F}}-\delta \boldsymbol{F} ; \quad \delta \boldsymbol{F} \rightarrow \delta \boldsymbol{T}, \delta \boldsymbol{\Phi}(t), \delta \boldsymbol{R}(t)$ - referencinèse stotyse nustatytų atitinkamų dydžių pataisų vektoriai.

Parametrinių lygčių koeficientų matricai $\boldsymbol{A}$ sudaryti taikomos redukuotos apytikrès referencinių stočių koordinatès. Naudojamas tam tikros teritorijos referencinių stočių tinklas. Taikant koordinačių pataisų, nešlio fazių skirtumų pataisų ar pseudoatstumų pataisu modelius matricos $\boldsymbol{A}$ išraiškos yra šiek tiek skirtingos.

Pataisų lygčių sistema (5) sprendžiama mažiausiuju kvadratų metodu, ir gaunamas išlygintuju parametru reikšmių vektorius:

$$
\tau=N^{-1} A^{T} P \delta F,
$$

čia $\boldsymbol{N}=\boldsymbol{A}^{\boldsymbol{T}} \boldsymbol{P A}-$ normalinių lygčių koeficientų matrica, $\boldsymbol{P}$ - atitinkamų dydžių pataisų svorių matrica.

Apskaičiuotų parametrų reikšmių vektoriaus $\tau$ tikslumas iqvertinamas jų kovariacijų matrica:

$$
\boldsymbol{K}_{\tau}=\sigma_{0}^{2} \boldsymbol{N}^{-1}
$$

čia $\sigma_{0}-$ matavimo rezultato, kurio svoris lygus vienetui, standartinis nuokrypis.
Standartinio nuokrypio ịvertis $m_{0}$ nustatomas iš formulès

$$
\sigma_{0}^{2} \approx m_{0}^{2}=\frac{1}{n-k} \boldsymbol{V}^{T} \boldsymbol{P} \boldsymbol{V}
$$

čia $n$ - pataisų lygčių skaičius, $k$ - parametrų skaičius.

GPS virtualiosios referencinès stoties regresinio modelio parametrų reikšmių vektorius $\tau$ taikomas nustatant naudotojų GPS imtuvais tikslias taškų koordinates. Skaičiavimų formule:

$$
\delta \boldsymbol{F}_{S}=\boldsymbol{A}_{S} \boldsymbol{\tau}
$$

čia $\delta \boldsymbol{F}_{S}-s$-tojo taško koordinačių pataisų, nešlio fazių skirtumų pataisų ar pseudoatstumų pataisų vektorius; $\boldsymbol{A}_{S}-$ koeficientu matrica, formuojama pagal vartotoju imtuvais nustatytas redukuotas apytikres taškų koordinates $\left(X_{S}^{\prime}, Y_{S}^{\prime}, Z_{S}^{\prime}\right)$.

Vektoriaus $\delta \boldsymbol{F}_{S}$ kovariacijų matrica yra lygi

$$
\boldsymbol{K}_{\delta \boldsymbol{F}_{S}}=\boldsymbol{A}_{S} \boldsymbol{K}_{\tau} \boldsymbol{A}_{S}^{T}=\sigma_{0}^{2} A_{S} N^{-1} \boldsymbol{A}_{S}^{T}
$$

\section{GPS virtualiosios referencinès stoties modelis taikant koordinačių korektūrą}

Šiam modeliui sudaryti taikomos žinomos tiksliosios referencinių stočių koordinatès bei jų apytikslès koordinatès, nustatytos atitinkamą epochą. Rašoma bendroji referencinių stočių parametrinių pataisų lygčių sistema (5)

$$
\boldsymbol{V}=\boldsymbol{A} \tau-\delta \boldsymbol{T}
$$

čia $\quad V=\delta \tilde{T}-\delta T-$ pataisų vektorius, $\delta \boldsymbol{T}=$ $\left(\delta \boldsymbol{T}_{1}, \ldots, \delta \boldsymbol{T}_{n}\right)^{\boldsymbol{T}}-n$-tosiose referencinėse stotyse nustatytu koordinačiu pataisu vektorius, $\delta \boldsymbol{T}_{\boldsymbol{i}}=\tilde{\boldsymbol{T}}_{\boldsymbol{i}}-\boldsymbol{T}_{\boldsymbol{i}}=$ $\left(\tilde{X}_{i}-X_{i}, \tilde{Y}_{i}-Y_{i}, \tilde{Z}_{i}-Z_{i}\right)^{T}$. Parametru vektoriu $\tau$ ivertinsime dviem variantais, kai:

$$
\text { 1. } \boldsymbol{\tau}=\left(t_{1}, t_{2}, t_{3}, t_{4}, t_{5}, t_{6}\right)^{T}, k=6-\text { parametruc skai- }
$$
čius,

$$
\text { 2. } \boldsymbol{\tau}=\left(t_{1}, t_{2}, t_{3}, t_{4}, t_{5}, t_{6}, t_{7}, t_{8}, t_{9}\right)^{T}, k=9 .
$$

Pataisų lygčių koeficientų matrica $A$ turi blokini pavidalą:

$$
\boldsymbol{A}=\left(\begin{array}{l}
\boldsymbol{A}_{1} \\
\boldsymbol{A}_{2} \\
\vdots \\
\boldsymbol{A}_{\boldsymbol{n}}
\end{array}\right),
$$

čia $n$-referencinių stočių skaičius.

Pavienès $i$-tosios referencinès stoties blokinè dalis $\boldsymbol{A}_{i}$ yra lygi 


$$
\boldsymbol{A}_{i}=\left(\begin{array}{c}
A_{x i} \\
A_{y i} \\
A_{z i}
\end{array}\right)
$$

Pagal pirmaji variantą blokinę dali $\boldsymbol{A}_{i}$ užrašome regresiniu pavidalu:

$$
\boldsymbol{A}_{i}=\left(\begin{array}{c}
A_{x i} \\
A_{y i} \\
A_{z i}
\end{array}\right)=\left(\begin{array}{cccccc}
X_{i}^{\prime} & Y_{i}^{\prime} & Z_{i}^{\prime} & X_{i}^{\prime 2} & 0 & 0 \\
X_{i}^{\prime} & Y_{i}^{\prime} & Z_{i}^{\prime} & 0 & Y_{i}^{\prime 2} & 0 \\
X_{i}^{\prime} & Y_{i}^{\prime} & Z_{i}^{\prime} & 0 & 0 & Z_{i}^{\prime 2}
\end{array}\right)
$$

Pagal antraji variantą blokinè dalis $\boldsymbol{A}_{i}$ yra:

$$
\begin{aligned}
& A_{i}=\left(\begin{array}{c}
A_{x i} \\
A_{y i} \\
A_{z i}
\end{array}\right)=\left(\begin{array}{cccccc}
X_{i}^{\prime} & Y_{i}^{\prime} & Z_{i}^{\prime} & X_{i}^{\prime 2} & 0 & 0 \\
X_{i}^{\prime} & Y_{i}^{\prime} & Z_{i}^{\prime} & 0 & Y_{i}^{\prime 2} & 0 \\
X_{i}^{\prime} & Y_{i}^{\prime} & Z_{i}^{\prime} & 0 & 0 & Z_{i}^{\prime 2}
\end{array} \rightarrow\right. \\
& \left.\rightarrow \begin{array}{ccc}
\left(X_{i}^{\prime} Y_{i}^{\prime}\right) & 0 & 0 \\
0 & \left(X_{i}^{\prime} Y_{i}^{\prime}\right) & 0 \\
0 & 0 & \left(X_{i}^{\prime} Y_{i}^{\prime}\right)
\end{array}\right)
\end{aligned}
$$

Redukuotosios referencinių stočių koordinatès gaunamos iš lygybių:

$$
\begin{aligned}
& X_{i}^{\prime}=X_{i}-X_{0}, \\
& Y_{i}^{\prime}=Y_{i}-Y_{0}, \\
& Z_{i}^{\prime}=Z_{i}-Z_{0},
\end{aligned}
$$

čia $X_{0}, Y_{0}, Z_{0}$ - referencinių stočių tinklo mažiausiosios apvalintosios koordinačių reikšmès.

Abiejų variantų atvejais pataisų lygčių sistemos (11) sprendžiamos mažiausiujų kvadratų metodu, ir gaunamas parametrų reikšmių vektorius:

$$
\tau=N^{-1} A^{T} P \delta T,
$$

čia $\boldsymbol{N}=\boldsymbol{A}^{\boldsymbol{T}} \boldsymbol{P A}$. Kiekvienam variantui taikoma sava matrica $A$.

Apskaičiuotų parametrų reikšmių vektoriaus $\boldsymbol{\tau}$ tikslumas (kiekvieno varianto) ivvertinamas jų kovariaciju matricomis pagal formulę:

$$
\boldsymbol{K}_{\tau}=\sigma_{0} N^{-1} .
$$

GPS imtuvo naudotojas, nustatydamas savo vietovès tašku koordinates, gali taikyti virtualiosios referencinès stoties regresinio modelio parametrų reikšmių vektorių $\tau$ ir apskaičiuoti apytikrių koordinačių pataisų vektorių -

$$
\delta T_{S}=A_{S} \tau,
$$

čia $\boldsymbol{A}_{S}$ - koeficientu matrica, sudaroma pagal vartotoju imtuvais nustatytas apytikres taškų koordinates $\left(X_{S}^{\prime}, Y_{S}^{\prime}, Z_{S}^{\prime}\right)$, taikant vieną iš minètujų dviejų variantų.

Tokie skaičiavimai galimi GPS virtualiojoje stotyje arba GPS vartotojo imtuve, taikant telemetrinio ryšio priedèli. Pirmuoju atveju virtualioji stotis transliuoja koordinačių pataisas, o antruoju - parametrų reikšmių vektoriu $\tau$.

Tikslių s-tojo taško koordinačių vektorius bus lygus

$$
\tilde{\boldsymbol{T}}_{S}=\boldsymbol{T}_{S}+\boldsymbol{\delta} \boldsymbol{T}_{S}=\left(\begin{array}{c}
\tilde{X}_{S} \\
\tilde{Y}_{S} \\
\tilde{Z}_{S}
\end{array}\right)=\left(\begin{array}{c}
X_{S} \\
Y_{S} \\
Z_{S}
\end{array}\right)+\left(\begin{array}{c}
\delta X_{S} \\
\delta Y_{S} \\
\delta Z_{S}
\end{array}\right) .
$$

5. GPS virtualiosios referencinès stoties modelis taikant nešlio fazių skirtumų bei pseudoatstumų pataisas

Parametriniu pataisų lygčių sistemos, taikant fazių skirtumus ir pseudoatstumus, rašomos:

$$
\begin{aligned}
& \boldsymbol{V}_{\varphi}=\boldsymbol{A} \boldsymbol{\tau}_{\varphi}-\boldsymbol{\delta} \boldsymbol{\Phi}, \\
& \boldsymbol{V}_{R}=\boldsymbol{A} \boldsymbol{\tau}_{R}-\boldsymbol{\delta} \boldsymbol{R},
\end{aligned}
$$

čia $\boldsymbol{\delta} \boldsymbol{\Phi}, \boldsymbol{\delta} \boldsymbol{R}$ - nešlio fazių skirtumų bei pseudoatstumu pataisu vektoriai.

Pataisu lygčiu koeficientu matrica $\boldsymbol{A}$ turi blokini pavidalą $\boldsymbol{A}=\left(\boldsymbol{A}_{1} \boldsymbol{A}_{2} \ldots \boldsymbol{A}_{n}\right)^{T}$. Blokinè dalis $\boldsymbol{A}_{\boldsymbol{i}}$ priklauso $i$-tajai referencinei stočiai, tad ir sudaroma dviem variantais:

1. $A_{i}=\left(X_{i}^{\prime} Y_{i}^{\prime} Z_{i}^{\prime} X_{i}^{\prime 2} Y_{i}^{\prime 2} Z_{i}^{\prime 2}\right)$,

2. $\boldsymbol{A}_{i}=\left(X_{i}^{\prime} Y_{i}^{\prime} Z_{i}^{\prime} X_{i}^{\prime 2} Y_{i}^{\prime 2} Z_{i}^{\prime 2}\left(X_{i}^{\prime} Y_{i}^{\prime}\right)\left(X_{i}^{\prime} Z_{i}^{\prime}\right)\left(Y_{i}^{\prime} Z_{i}^{\prime}\right)\right)$.

Blokinès dalys $\boldsymbol{A}_{i}$ yra vienodos taikant nešlio faziu skirtumų ar pseudoatstumų pataisų nustatymo formules.

Apytikrès redukuotosios koordinates $\left(X_{i}^{\prime} Y_{i}^{\prime} Z_{i}^{\prime}\right)$ skaičiuojamos pagal anksčiau aprašytas formules.

Parametrų reikšmių vektoriai $\boldsymbol{\tau}_{\varphi}$ ir $\boldsymbol{\tau}_{R}$ skaičiuojami mažiausiujų kvadratų metodu kiekvienam variantui:

$$
\begin{aligned}
\tau_{\varphi} & =N_{\varphi}^{-1} A^{T} P_{\varphi} \delta \Phi, \\
\tau_{R} & =N_{R}^{-1} A^{T} P_{R} \delta R,
\end{aligned}
$$

čia $\quad N_{\varphi}=A^{T} P_{\varphi} A ; \quad N_{R}=A^{T} P_{R} A ; \quad P_{\varphi}, P_{R}$ - atitinkamai nešlio fazių skirtumų bei pseudoatstumų pataisų svorių matricos.

Parametrų reikšmių vektorių $\boldsymbol{\tau}_{\varphi}$ ir $\boldsymbol{\tau}_{\boldsymbol{R}}$ tikslumas pagal kiekvieną variantą ịvertinamas ju kovariaciju matricomis: 


$$
\begin{aligned}
\boldsymbol{K}_{\tau_{\varphi}} & =\sigma_{0}^{2} \boldsymbol{N}_{\varphi}^{-1}, \\
\boldsymbol{K}_{\tau_{\boldsymbol{R}}} & =\sigma_{0}^{2} \boldsymbol{N}_{\boldsymbol{R}}^{-1} .
\end{aligned}
$$

Pagal kovariaciju matricu $\boldsymbol{K}_{\tau_{\varphi}}$ ir $\boldsymbol{K}_{\tau_{\boldsymbol{R}}}$ ỉverčius kiekvieno varianto atveju galima daryti išvadas apie gautų parametrų reikšmių tikslumą.

\section{Išvados}

1. Siūloma virtualiosios referencinès stoties regresiniu lygčių parametrų reikšmes nustatyti tais atvejais, kai skaičiavimuose taikomi koordinačiu, nešlio fazių skirtumų ir pseudoatstumų pataisų modeliai.

2. Regresiniu lygčiu parametrų vektorių reikšmès, nustatytos taikant koordinačių pataisų modeli, yra tikslesnès nei taikant nešlio fazių skirtumu bei pseudoatstumų pataisų modelius. Taip atsitinka todèl, kad regresinių lygčių skaičius yra tris kartus didesnis, taikant koordinačių pataisų modeli

\section{Literatūra}

1. Lambert Wanninger. Virtuelle GPS-Referenzstationen für grossräumige kinematische Anwendungen. Zeitschrift für Vermessungswesen, No 3. Stuttgart: Verlag K. Witwer, 2003, S. 196-202.

2. Hankemeier, P. Der Satellitenpositionierungsdienst SAPOS in Deutschland. Multifunktionale GNSSReferenzstationsysteme für Europa. Workshop von 4-5 März 2002 in der Europäischen Akademie für städtische Umwelt. Berlin, 2002, S. 16-23.
3. Teunissen, P. J. G. The parameter distributions of the integer GPS model. Journal of Geodesy, No 1 (76), 2002, p. 41-48.

4. Skeivalas, J. Accuracy determination of the coordinates augmentations of GPS vectors by measuring double phase shifts of the carrier. Geodesy and Cartography (Geodezija ir kartografija), Vol XXIX, No 4, 2003, p. 115-118 (in Lithuanian).

5. Bauer, M. Vermessung und Ortung mit Satelliten. Heidelberg: Wichmann, 1994. 274 S.

6. Hofmann-Wellenhof, B.; Lichtenegger, H. and Collins, J. Global Positioning System. Wien, New York: SpringerVerlag, 1992. 326 p.

7. Leick, A. GPS Satellite Surveying. New York, Chichester, Brisbane, Toronto, Singapore: John Wiley and Sons, 1995. $352 \mathrm{p}$.

8. Koch, K. R. Einführung in die Bayes-Statistik. SpringerVerlag, Berlin Heidelberg, 2000. 225 S.

9. Markuze, J. I. Algorithms for geodetic networks adjustment using computers (Алгоритмы для уравнивания геодезических сетей на ЭВM). Moscow: Nedra, 1989. 248 p. (in Russian).

10. Gao, Y.; and Liu, Z. Z. Precise Ionosphere Modeling Using Regional GPS Network Data. Journal of Global Positioning Systems, Vol 1, No 1, 2002, p. 18-24.

Jonas SKEIVALAS. Prof, Doctor Habil.

Vilnius Gediminas Technical University. Dept of Geodesy and Cadastre, Sauletekio al. 11, LT-10223 Vilnius, Lithuania $(\mathrm{Ph}+3705274$ 4703, Fax +370 5274 4705),

e-mail: jonas.skeivalas@ap.vtu.lt.

Author of two monographs and more than 130 scientific papers. Participated in many intern conferences and research visits to the Finish Geodetic Institute.

Research interests: processing of measurements with respect to tolerances, adjustment of geodetic networks. 